INTERNATIONAL DESIGN CONFERENCE - DESIGN 2018

https://doi.org/10.21278/idc.2018.0194

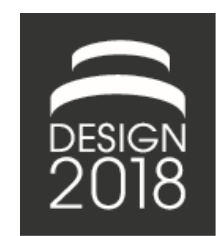

\title{
SUPPORTING PRODUCT DEVELOPMENT AT TECH STARTUPS WITH LEAN PRODUCT DEVELOPMENT: CHALLENGES AND OPPORTUNITIES
}

\author{
M. Van Der Braak, J. M. Jauregui Becker and M. V. P. Pessoa
}

\begin{abstract}
Startups and Small and Medium Enterprises (SME) are the backbone of the European society, accounting for $67.1 \%$ of the total employment. One of the main common challenges for startups is product development (PD). While the Lean PD (LPD) approach has been proved effective in bigger companies, very few work was done related to SME and particularly to startups. In this work, a survey was sent to 104 Dutch tech startups. The results from the 26 respondents supported identifying a set of opportunities and challenges on reframing lean to startups.
\end{abstract}

Keywords: product development, lean product development, small and medium size enterprise (SME), startups

\section{Introduction}

As a consequence of today's increasingly dynamic markets, most companies are under pressure to develop new products in shorter times while maintaining a high quality (Rauch et al., 2017). In order to stay competitive in fast-paced markets such as high-tech, medical and consumer goods, product development (PD) has become crucial at the moment of setting up company strategies for long term survival, as development time and costs are becoming increasingly important (Tortorella et al., 2016; Rauch et al., 2017).

Startups and Small and Medium Enterprises (SME) are the backbone of our society, representing 99.8\% of the non-financial enterprises in the EU-28 and accounting for $67.1 \%$ of the total employment (Eurostat, 2017). The main focus of the research is around startups as they are seen as the drivers of European innovation producing around 50\% of all new jobs (Kollmann et al., 2016). To differentiate between SMEs and startups, who often fall within the same size category, a set of three distinctive startup characteristics are defined; younger than 10 years, feature (highly) innovative technologies and/or business models and have (or strive for) significant employee and/or sales growth (Kollmann et al., 2016). Startups are known for having a strong flexibility, horizontal organizational structures, and limited bureaucracy, which enables rapid decision making and therefore the development of highly innovative products and services (Vossen, 1998; Flores et al., 2011). On the downside, startups often lack resources and budget, knowledge, and experience, which gives the employees the tendency to act based on intuition, and insufficient documentation. As a consequence, startups have to deal with an uncertain and turbulent environment (Vossen, 1998; Flores et al., 2011). Consistent development of new products is vital for long term survival, business growth and prosperity, being one of the key success factors for many enterprises (Owens, 2007). Startups are often build around a product which highlights the importance of PD as it can make or break the company. The European Startup Monitor (ESM) annually researches startups located in Europe. 
According to ESM 2016 (Kollmann et al., 2016), the biggest common challenges startups have to deal with are sales/customer acquisition (19.6\%), product development (17.1\%) and growth (16.6\%).

One way to deal with the afore mentioned challenges, i.e. shorter product life cycles, is by applying a Lean Product Development (LPD) approach. LPD focuses on creating value, eliminating waste, capturing and re-using (tacit) knowledge and continuous improvement (Kaizen) by the use of multiple principles and enablers. PD plays an important part in translating the customer needs and wishes into customer value by means of a service and/or product (Morgan and Liker, 2006, p. 9). It determines the physical appearance of the product, defines the materials to be used and, thus, largely constrains the set of production processes which can be employed to manufacture the product (Hoppmann et al., 2011). As a result of this, PD has a direct impact on costs, product quality, time-to-market and customer satisfaction. While lean manufacturing has been extensively applied, researched, and documented on literature, there is comparably less research on how to apply lean to the product development process (PDP) (Rauch et al., 2017). Research on how to implement LPD mostly discusses large companies. Empirical research on startups and their PD is scarce. So, a knowledge gap on implementing LPD to startups is present.

This research aims at investigating where LPD could support startups with their PD to create high quality products faster which increases their survival rate. By researching how LPD currently is implemented in startups, a better understanding of PD and the opportunities for lean is created. In turn, this can provide insights into how their PDPs can be supported and improved with the goal of increasing their rate of long term survival. The paper presented identifies which of the challenges, that startups face, can be addressed by using LPD tools and techniques. Based on a survey distributed to tech startups within the Netherlands, the sample data is translated into challenges and opportunities. The results of this research can be used for the following three purposes: 1) providing startups information and insight on where LPD could be incorporated into their own company by identifying common characteristics and challenges, 2) providing new insights on how startups do their PD on which further lean initiatives and research regarding (tech) startups and SMEs can be built on and finally 3) the defined challenges and opportunities aim to inspire startups, SMEs, and the academic world to look critically at LPD and PDP's. This paper is organized as follows. Section 2 discusses the different LPD models based on previously performed researches. Section 3 deliberates maturity models for small companies and startups. In Section 4 the research method, distribution and survey design are explained. Section 5 shows the results of the survey and shortly discusses the results. Section 6 the results are discussed and analysed to define a set of recommendations on how to introduce LPD to startups. Finally, Section 7 states the conclusion, limitations and recommendations for future research.

\section{Organizing the lean product development system}

This section starts with discussing the Lean philosophy and various LPD frameworks defined by previous researchers. After this, current (lean) startups models are elaborated for creating a holistic view.

\subsection{Lean thinking and product development}

Lean thinking is the fundamental philosophy in which reducing waste and increasing value are its core values (Womack and Jones, 2003). It is the basis on which lean "fields" such as manufacturing and product development are based on. This is achieved by having a continuously flowing value stream in which there is a minimal waste of resources. The most commonly used model of describing lean is based on its five major principles: identify value, map the value stream, create flow, establish pull and seek perfection, as stated in the book "Lean Thinking" by Womack and Jones (2003).

There are multiple researchers who tried to define a complete set of LPD principles, tools and techniques to cover the PDP such as (Morgan and Liker, 2006; Khan et al., 2013; Ward and Sobek, 2014). However, as of today, most researches are strongly focussed on tools and techniques present at Toyota (Hoppmann et al., 2011). Currently, there is no consensus among those researchers on which set of principles provides a clear, structured and complete framework. The defined set of principles are showing overlapping characteristics but none is seen as the generally accepted approach (Hoppmann et al., 2011). Morgan and Liker (2006) were one of the first to describe a set of basic principles on how to implement LPD. Their set of principles is based on years of research and working closely together with Toyota 
(Morgan and Liker, 2006, p. 4). In total 13 principles have been described which are divided into three primary subsystems: people, process and tools \& technology. In 2007, Ward and Sobek (2014) define five LPD principles aimed to create profitable operational value streams predictably, effectively, and efficiently through usable knowledge. These principles are defined as: focus on creating knowledge, entrepreneurial system designer, set-based concurrent engineering, teams of responsible experts, and cadenced flow and pull management. In 2011, Khan et al. (2013) defined a LPD model consisting of five principles from. They defined a model based on analysing and prioritizing previously defined frameworks. These principles include Set-Based Concurrent Engineering (SBCE), chief engineer and technical leadership, valuefocussed planning \& development, knowledge-based environment and continuous improvement (Kaizen). Schuh et al. (2011) defined three primary subsystems focusing on structure early, synchronize easily and adapt securely. A total of 10 principles are defined and categorized under those primary subsystems. Hoppmann et al. (2011) and Dombrowski and Zahn (2011) both analysed multiple existing LPD principles and methods and compared them to find relations. Both resulted in a framework of 11 and 7 principles respectively. More recently, Tortorella et al. (2016) described a set of four principles; SBCE, value focus, knowledge focus and continuous improvement. Aikhuele and Turan (2016) added more principles such as the adoption of a chief engineer and cross-functional teams, poka-yoke and supplier integration.

\subsection{Current (lean) startup models}

As of today, there is one startup methodology called "The Lean Startup" which incorporates lean principles to increase the startup success rate and shortening the PDP (Ries, 2011). The main focus of this methodology are build-measure-learn cycles for obtaining measurable results and developing a Minimum Viable Product (MVP). MVP is the smallest product that can be released that delivers customer value and provides maximum feedback for future PD (Ries, 2011). The Lean Startup became increasingly popular which comes with criticism. Criticism on the methodology includes that it does not specifically describe how customer input can be collected and qualitative feedback evaluation needs more emphasis (Müller and Thoring, 2012; Radeka, 2015). Other methodologies that are commonly used at startups to improve their PD and thus the success rate are Agile and Scrum which focuses on short iteration cycles and daily meetings. Overall, lean provides a more holistic approach than agile because it influences all types of losses (not only time loss) such as money, labour, and energy (Nedre, 2018). Lean is about cultural change that goes beyond the PD activities (Morgan and Liker, 2006) while agile is more of a technique aimed at executing tasks faster to make adapting to changes easier (Nedre, 2018). Finally, "Rapid Learning Cycles" by (Radeka, 2015), which is aimed at companies in general, is oriented at creating learning cycles. They combine "The Lean Startup" methodology with the Look Ask Model Discuss Act (LAMDA) learning cycle originating from (Ward and Sobek, 2014).

\section{Maturity models for small companies and startups}

In order to implement LPD to tech startups, literature research is done to obtain a clear view of their characteristics, the different maturity phases and the challenges and opportunities each phase brings. Collecting this information is used to align the different startup maturity phases with LPD models which creates the main guideline for developing the survey.

\subsection{Startup characteristics}

Different types of startups have been defined in literature. For example, a distinction can be made between university spin-offs, company spin-offs, spin-off from other research institutions and independent venture creation. High-tech university spin-offs are generally able to quickly develop and grow. Connection with a university enables startups to have higher productivity rates, profits, and investment due to student assistance, faculty expertise, and the university facilities and networks (Stayton and Mangematin, 2016). Management wise, university spin-offs often lack managerial and commercial experience which becomes crucial once a startup starts to grow in size. Internal and external management structures evolve rapidly and new sets of skills are required (Vohora et al., 2004).

Entrepreneurs in general are highly motivated, are frequently communicating with others, are willing to make long working days and have to cope with high stresses and uncertainties. Being passionate about 
their product or service in development causes their physical and mental energies to be absorbed entirely (Lewis and Churchill, 1983; Stayton and Mangematin, 2016). Often too much emphasis is placed on developing the technology and too little on identifying, accessing and targeting key customers in the value chain (Vohora et al., 2004). In the first phases of a startup, there is not enough time to recruit the best possible candidates, to build relationships and trust, or to develop formal agreements that can take the place of informal trust (Stayton and Mangematin, 2016). A recent research who investigated four fast developed startups showed that common characteristics are (Stayton and Mangematin, 2016):

- Motivation for speed; time and financial pressure motivates startups to start up quickly so they can generate revenue before they run out of funds. The right introduction of a product or service has a large impact on the success. Entrepreneurs are aware that time is limited and valuable as it cannot be bought, activities can only be compressed.

- Startup team composition; the initial entrepreneurial teams are often sourced from people they already knew.

- Workload pressures; workload is high among entrepreneurs. There are multiple risks and uncertainties during the development of product/service which mentally drains the team members. Everyone wants the startup to succeed.

- Early startup team departures; a high workload in combination with a moderate to low salary creates early departures from team members. Team members have to care for themselves.

\subsection{Startup maturity/phasing models}

Startup companies are diverse and might not seem to have much in common when it comes to modelling the different phases. However, there are general factors which affect most of these companies such as time pressure and the organization of management. Multiple researches tried to identify which phases are commonly occurring within startups and small companies.

In 1983 (Lewis and Churchill, 1983) saw the need to develop a maturity framework to aid smaller companies in addressing current challenges, diagnosing problems and matching solutions. Based on experience, literature and empirical research, they developed a framework with five stages of development; existence, survival, success-disengagement, success-growth, take-off and resource maturity. (Scott and Bruce, 1987) defined a framework of five stages of growth in small companies, which looks similar to the one from Churchill and Lewis. During a crisis, a company has to gain certain resources and adapt the management structure and capabilities in order to succeed. They state that majors concerns in moving from one stage of development to the next are: 1) handling the crisis itself and 2) if succeeded, how to manage the "new" company (Scott and Bruce, 1987).

When looking at startups specifically, (Vohora et al., 2004) searched into the framework of university spin-offs and how this specific type of startup grows together with its challenges. Vohora defines five phases in which the third phase, pre-organization, is seen as having the steepest learning curve for an academic entrepreneur. In line with (Scott and Bruce, 1987), it recognizes that critical junctures occur before the next phase can start.

More recently, Stayton and Mangematin (2016) aimed to understand how some technology startups are able to develop innovative products, form organizations and internationalize very rapidly. They highlight the implications for university-sourced startups and concluded that "reducing startup time increases the riskiness of the organizational emergence while improving domestic and international market prospects. Time is not only a source of tension. Time is a key variable to be strategically managed." (Stayton and Mangematin, 2016). The findings of the research created a framework in which two parallel processes are mapped, product (six phases) and organizational emergence (four phases).

\section{Test methodology}

This study is exploratory in nature and aims to create a better understanding on how LPD could support startups with their PD with the goal of creating high quality products faster. Gaining insight into which challenges startups face during the PDP, mapping the current maturity state and how product development is currently organized are key characteristics this study aims at identifying. Due to its exploratory nature, the research strategy was decided to be in the form of a survey that contains closed questions varying 
between leading, Likert and multiple choice questions. Questions related to LPD are asked based on the Start-Awareness-Unstructured-Continued-Evolved (SAUCE) (Al-Ashaab et al., 2015) scaling model. This method measures the implementation of lean principles in a company by defining five levels of leanness.

\subsection{Survey design}

The questions were consciously written omitting the use of any lean jargon (e.g. SBCE, Just-In-Time (JIT)), as it results in the following two benefits (Al-Ashaab et al., 2015):

- Prevents unwanted confusion and makes the survey easier to understand. Not every participant knows the definition.

- Ensures that participants are not influenced or restricted by comparing the questions to their own practises and experiences. This decreases the subjectivity.

Based on the literature review and the defined goal the questions are selected and worked out. Both the startup phase models and their characteristics are compared with the different discussed LPD methods in order to find commonly shared areas. The commonly shared areas represent which methods show the greatest potential for reaching the goal of the survey. It maps and links the characteristic needs from the startup maturity models with LPD methods. To check if nothing is missing and if the questions do not cause confusion when filling in, a pilot study is organized. In this pilot study, three tech startups participated from which one is a university startup from the University of Twente and two are independent startups. The feedback from different types of startups, who are likely to have a slightly different mindset, are registered and used to improve the survey. Figure 1 shows a visualization of the steps taken to develop, execute, and analyse the results.

Questions asked are organized according to their subject. The survey consists of three sections:

- General information; provides background information used to organize and categorize the startups based on different industrial sectors, product complexity and size.

- Startup maturity and challenges; obtains information about the organizational structure, management style, revenue and past-current challenges.

- Current LPD knowledge and product development process; maps the current implementation of the five principles described by Khan et al. (2013) and gains insight into different types of waste occurring during PD. The causes of poor performance are based on the original seven types of waste as defined in lean thinking (Pullan et al., 2013).

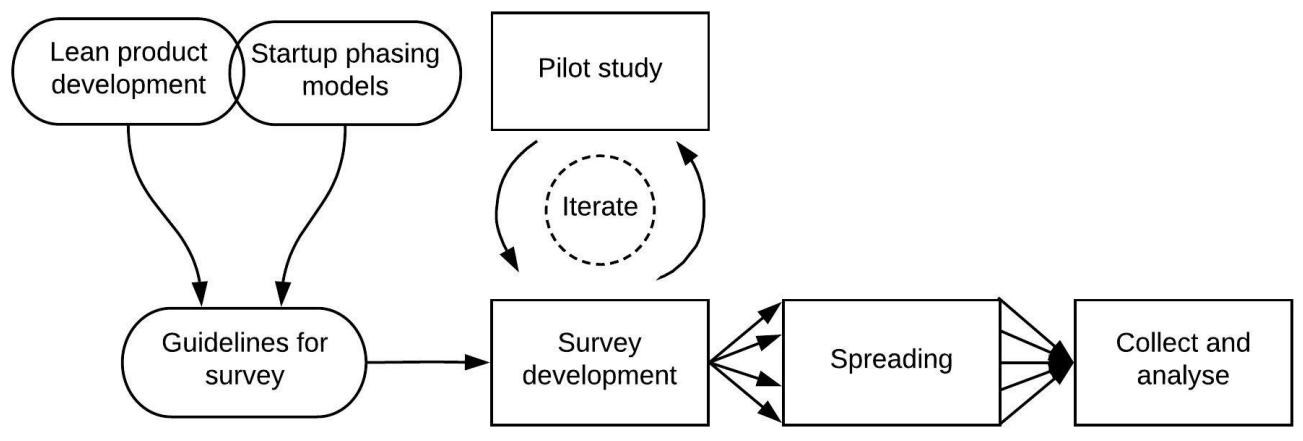

Figure 1. The process of developing the survey

\subsection{Sample selection and spreading survey}

The data in the survey originates from a sample of tech startups located in the Netherlands. Other geographical locations are not taken into account due to expected cultural differences. Technical oriented startups are selected based on information provided by startup hubs, personal connections and Startup Delta who presents a startup database visualized in an interactive map.

The survey was sent by email to a total of 104 companies. In order to increase the response rate, companies received a reminder after one week and received a second reminder after three weeks. After 4 weeks the survey closed and the responses were collected and analysed. Additionally, startups located in the region of Twente, the Netherlands, were approached using a local startup hub newspaper. 


\section{Results}

This section describes the results from the distributed survey. Not all results are and can be discussed in this publication. However, the focus of the findings was placed on those results that provide statement of creating a better understanding on PD and the opportunities for lean.

\subsection{Response rate}

The total number of responses received from the 104 invitations was 26 which gave a response rate of $25.0 \%$. Reasons why this percentage is rather low is likely to be related to the length of the survey, as it takes about 15 minutes to complete, and the fact that startups are busy entrepreneurs.

\subsection{General information}

The sample represents startups from a spectrum of industrial sectors from which industrial technology/production/hardware (50.0\%) and bio-, nano-, and medical technology (19.3\%) are the most represented areas in this survey. Most startups are founded independently $(57.7 \%)$ followed by university startups (34.6\%). The size of the startups differs from 1-2 employees to 50 or more. As revenue is one of the main challenges, startups were asked to fill in how many employees were working for the company and how many are being paid. Results indicate that the smaller startups are more likely to have unpaid work than the larger (20+ employees) startups.

\subsection{Startup maturity and challenges}

To determine the maturity of the startups and their challenges questions about the organizational structure and management style were asked. Results from the survey, see Figure 2, show that both the organizational structures and the management style in startups are basic, simple and entrepreneurial as $80.8 \%$ identify their organizational structure as having one or two hierarchy levels.

Another question in the survey was about generating revenue. Most startups are either close to generating their first revenue $(30.8 \%)$ or are generating a positive revenue but are investing most of it back into to company to enable grow (50.0\%). A small group has a positive revenue with high dividend $(7.7 \%)$ or has no revenue $(11.5 \%)$.

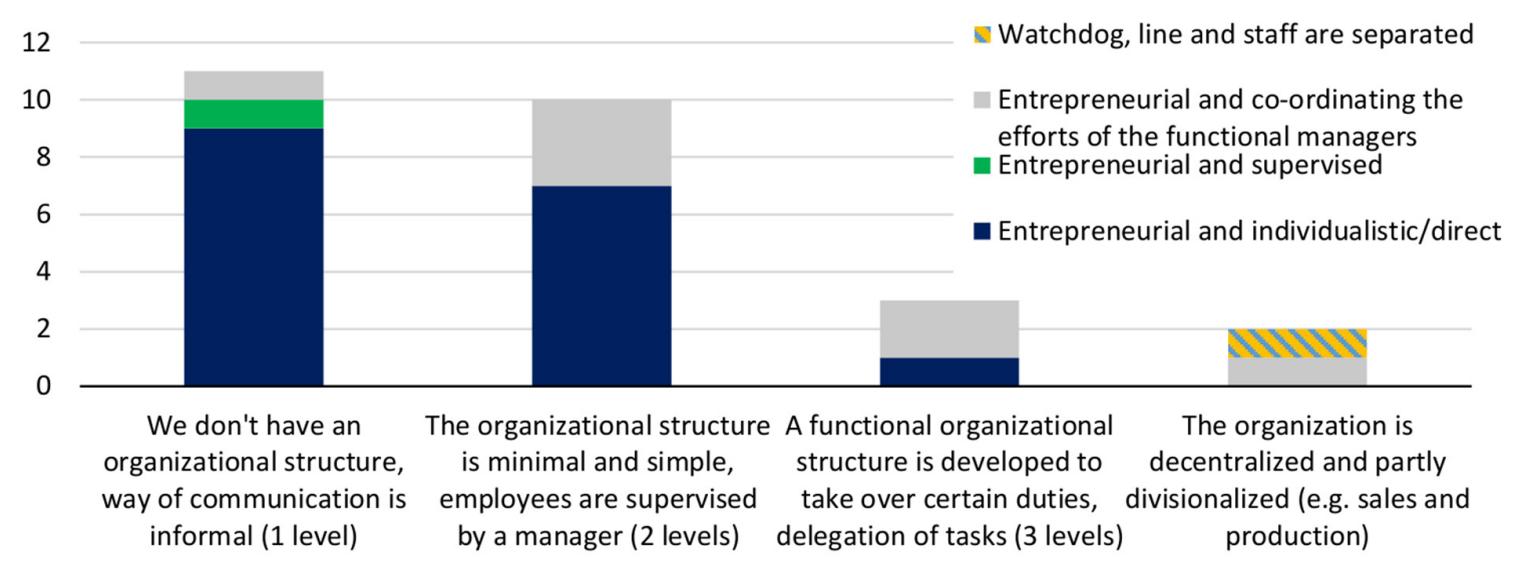

Figure 2. Organizational structure and management style within startups $(n=26)$

Startups were asked to write down their biggest challenge so far and which challenges they are currently facing. Challenges indicate where room for improvement is wanted and/or needed. The biggest challenges faced so far are summarized in Table 1. Results show that funding, development time and the transition to a new product development phase such as making a product production ready are the most commonly occurred challenges they experienced so far. Managing growth and strategy are follow ups. Table 2 summarizes the challenges startups currently are facing. The data shows that managing growth and introducing a product to the market are the most apparent challenges. 
Table 1. Biggest startup challenge so far

\begin{tabular}{|l|l|l|}
\hline Choices & Absolute frequency & Relative frequency (\%) \\
\hline Funding & 9 & 30.0 \\
\hline Transition to a new product development phase & 7 & 23.3 \\
\hline Development time & 5 & 16.7 \\
\hline Product safety & 3 & 10.0 \\
\hline Strategy, alignment of technical research to sale & 2 & 6.7 \\
\hline Growth & 2 & 6.7 \\
\hline Other (reducing cost price, getting new projects) & 2 & 6.7 \\
\hline & 30 & 100 \\
\hline
\end{tabular}

Table 2. Current challenges and/or issues

\begin{tabular}{|l|l|l|}
\hline Choices & Absolute frequency & Relative frequency (\%) \\
\hline Growth & 9 & 29.0 \\
\hline Introducing product to market & 7 & 22.6 \\
\hline Funding & 7 & 22.6 \\
\hline Hiring new employees & 3 & 9.7 \\
\hline Other (production, closing sales, product development) & 5 & 16.1 \\
\hline & 31 & 100 \\
\hline
\end{tabular}

\subsection{Experience and (in)direct use of lean product development}

One of the first questions asked was about previous and current experience with applying lean tools and techniques into their company and product development. Most of the participating startups indicate that they do implement lean to product development and manufacturing (34.6\%). A relative high amount $(26.9 \%)$ of the startups indicate that they implement lean to product development only. $19.3 \%$ haven't looked into it but does know what lean is. A small amount of startups do not know what lean is $(3.8 \%)$. Another question in the survey was about the involvement of the customer during the PDP and how the Voice of Customer (VoC) is translated to measurable product development specifications. Overall, startups remain close to the customer during PD as, on a Likert scale where the higher the number the better, $42.3 \%$ of the startups gives themselves a $5 / 5$ and $23.1 \%$ a $4 / 5.34 .6 \%$ of the startups scored a $2 / 5$ or $3 / 5$. Table 3 summarizes the results of how the $\mathrm{VoC}$ is translated into measurable product development specifications. 53.8\% indicated that they do not have or use a standardized approach and $26.9 \%$ defines measurable product development specifications on intuition.

Table 3. Translating the VoC to measurable product development specifications

\begin{tabular}{|l|l|l|}
\hline Choices & $\begin{array}{l}\text { Absolute } \\
\text { frequency }\end{array}$ & $\begin{array}{l}\text { Relative } \\
\text { frequency (\%) }\end{array}$ \\
\hline $\begin{array}{l}\text { We use specific tools such as matrices, checklists and critical to quality trees } \\
\text { to translate the voice of customer into product specifications and } \\
\text { requirements }\end{array}$ & 2 & 7.7 \\
\hline $\begin{array}{l}\text { We don't have a standardized approach of translating the voice of customer } \\
\text { into product specifications and requirements }\end{array}$ & 14 & 53.8 \\
\hline $\begin{array}{l}\text { The product specifications and requirements are translated from the voice of } \\
\text { customer by intuition }\end{array}$ & 7 & 26.9 \\
\hline Other & 3 & 11.5 \\
\hline & 26 & 100 \\
\hline
\end{tabular}

Re-using (tacit) knowledge is an important part of LPD as it helps to stand out in a competitive marked. Two questions regarding this topic were asked. The first one asked how gained knowledge after solving a problem was documented (Table 4 ). The results show that $38.5 \%$ does not document gained knowledge after solving a design problem and $15.4 \%$ does document the knowledge but does not share it with others. Secondly, there was asked how effective they think they reuse the gained knowledge from previous projects rated on Likert scale. This resulted in $26.9 \%$ scoring $3 / 5,50.0 \%$ scoring $4 / 5$ and $23.1 \%$ scoring $5 / 5$ where the higher the score the better. 
Table 4. Knowledge documentation after solving a design problem

\begin{tabular}{|l|l|l|}
\hline Choices & $\begin{array}{l}\text { Absolute } \\
\text { frequency }\end{array}$ & $\begin{array}{l}\text { Relative } \\
\text { frequency (\%) }\end{array}$ \\
\hline $\begin{array}{l}\text { The gained solution is not formally documented, it mostly stays in the } \\
\text { minds of the employees }\end{array}$ & 10 & 38.5 \\
\hline The gained solution is formally documented in a database & 1 & 3.8 \\
\hline $\begin{array}{l}\text { Knowledge is captured from the formally documented solution to obtain } \\
\text { insights for the future but is not shared to others }\end{array}$ & 4 & 15.4 \\
\hline $\begin{array}{l}\text { Knowledge is captured from the formally documented solution and is } \\
\text { shared throughout the company so all the members learn from it }\end{array}$ & 6 & 23.1 \\
\hline $\begin{array}{l}\text { Knowledge is captured from the formally documented solution, is shared } \\
\text { and reused to support decision making }\end{array}$ & 5 & 19.2 \\
\hline & 26 & 100 \\
\hline
\end{tabular}

Causes of poor performance in PD indicate where and which processes are not yet optimal. The options of causes of poor performance are sorted back to the original seven types of lean waste and is summarized in Table 5. Results show that waste related to over production, over processing and defects are the most present by presenting $67.4 \%$ of the causes while inventory and transport have little to none impact. Looking at the causes belonging to the seven types of waste, "working on too many projects", "product complexity and size" and "lack of standardization of processes" contribute the most.

LPD is known for chief engineers who is responsible for the entire development of a product from concept to launch. Questioned is if there is such a technical leader present and if so how this person is characterised based on four leadership models. $76.9 \%$ percent of the startups indicate that such a technical leader is present. Mapping the characteristics one a 1-4 scale show that the group facilitator fits the best scoring $70.0 \%$ and the bureaucratic manager fits the least with $5.0 \%$. Both system designer and system integrated score in-between.

Table 5. Causes of poor performance during PDP translated to the 7 types of waste

\begin{tabular}{|c|c|c|c|c|c|}
\hline \multirow{2}{*}{$\begin{array}{l}\text { Waste } \\
\text { Over production }\end{array}$} & \multirow{2}{*}{$\begin{array}{l}\text { Cause } \\
\text { Working on too many projects }\end{array}$} & \multicolumn{2}{|c|}{$\begin{array}{l}\text { Absolute } \\
\text { frequency }\end{array}$} & \multicolumn{2}{|c|}{$\begin{array}{l}\text { Relative } \\
\text { frequency }(\%)\end{array}$} \\
\hline & & 16 & \multirow[t]{3}{*}{20} & 18.0 & \multirow[t]{3}{*}{22.5} \\
\hline & Over design or providing unnecessary features & 3 & & 3.4 & \\
\hline & Redundant development, not reusing knowledge & 1 & & 1.1 & \\
\hline \multirow[t]{2}{*}{ Waiting } & Unclear decision criteria & 7 & \multirow[t]{2}{*}{13} & 7.9 & \multirow[t]{2}{*}{14.6} \\
\hline & Waiting for test results or process information & 6 & & 6.7 & \\
\hline Transport & A long hierarchical structure for decision making & 1 & 1 & 1.1 & 1.1 \\
\hline \multirow[t]{4}{*}{ Over processing } & Product complexity and size & 13 & \multirow[t]{4}{*}{23} & 14.6 & \multirow[t]{4}{*}{25.8} \\
\hline & Meetings without result or consensus & 6 & & 6.7 & \\
\hline & Failure to identify and manage design risks & 4 & & 4.5 & \\
\hline & Unnecessary data conversions & 0 & & 0 & \\
\hline \multirow[t]{3}{*}{ Inventory } & Unnecessary documents & 0 & \multirow[t]{3}{*}{$\mathbf{0}$} & 0 & \multirow[t]{3}{*}{$\mathbf{0}$} \\
\hline & Keeping more information than needed & 0 & & 0 & \\
\hline & Poor configuration management & 0 & & 0 & \\
\hline \multirow[t]{3}{*}{ Movement } & Lack of standardization of processes & 8 & \multirow[t]{3}{*}{15} & 9.0 & \multirow[t]{3}{*}{16.9} \\
\hline & $\begin{array}{l}\text { Decisions are being made by people who do not have } \\
\text { enough knowledge to make them well }\end{array}$ & 5 & & 5.6 & \\
\hline & Working with wrong/incomplete information & 2 & & 2.2 & \\
\hline \multirow[t]{5}{*}{ Defects } & All activities that start with "re" such as rework, redo... & 6 & \multirow[t]{4}{*}{17} & 6.7 & \multirow[t]{4}{*}{19.1} \\
\hline & Not testing to specifications & 5 & & 5.6 & \\
\hline & $\begin{array}{l}\text { Failure to understand and capture requirements or poor } \\
\text { understanding of customer needs }\end{array}$ & 4 & & 4.5 & \\
\hline & Under specifying & 2 & & 2.2 & \\
\hline & & \multicolumn{2}{|l|}{89} & \multicolumn{2}{|l|}{100} \\
\hline
\end{tabular}




\section{Discussion}

This section translates the data from the survey into information by analysing and comparing the data to previously performed research. Based on this, opportunities and challenges are summarized on how LPD can support startups with their PD.

\subsection{Contribution to this field}

\subsubsection{Maturity and organization of startups}

The importance of generating a positive revenue as fast as possible becomes clear as mainly the startups with $<20$ employees seem to struggle to generate enough revenue to pay themselves. When looking at the revenue's, $30.8 \%$ is close to generating their first revenue and $50.0 \%$ are generating positive revenue but mainly invest it back into the company. This indicates that those startups are in the first three stages of maturity (Lewis and Churchill, 1983; Stayton and Mangematin, 2016) and point out the need to develop a product fast if a startup wants to survive on long term. Also, the biggest challenge experienced so far is funding which takes up $30.0 \%$ of the responses. Once a startup starts to grow and develop, funding becomes a smaller problem yet is still prominent with $22.6 \%$ of the responses.

The lack of resources, as defined in previous researches (Vossen, 1998; Flores et al., 2011), becomes clear when looking at the current biggest challenges. Growth (29.0\%), funding $(22.6 \%)$ and introducing a product to the market $(22.6 \%)$ are the largest contributors. In order to grow and introduce a product into the market, resources and (marketing) knowledge is needed. These results are in line with the biggest startup challenges summarized by ESM which were sales/customer acquisition (19.5\%), product development (17.1\%) and growth (16.6\%) (Kollmann et al., 2016).

\subsubsection{Current usage of LPD tools and techniques}

Entrepreneurial startups naturally show characteristics that closely resemble lean such as actively involving the customer and having a person resembling as chief engineer. However, when looking at the characteristics of the chief engineers present at the startups, the focus is mainly on the group facilitator model which is seen as the most fitting model $70.0 \%$ of the times. A chief engineer according to Morgan and Liker (2006) is defined as mostly being a system integrator where he or she at times put on the hat of the other three models. This difference between the footprint and sample is plotted in Figure 3 (Morgan and Liker, 2006, p. 132). Reasoning to why this difference is present could be due to the relatively simple hierarchy structure and management style which decreases the need to be a system integrator. This is in line with previous research as a common characteristic of startups is to have an initial team sourced from people they already knew, trust, and know what their capabilities are (Stayton and Mangematin, 2016). However, once the startup starts to grow in size a shift toward a system integrator will be needed in order to maintain a controlled organization since the weak point of a group facilitator is lacking a strong technical vision (Morgan and Liker, 2006).

A high percentage of the questioned startups know lean and/or are currently using it which shows a large contrast between the research published by (Rauch et al., 2017) who surveyed Italian SME's to ask their opinion about lean and LPD. This difference could be caused by the type of startups present in the sample and differences in educational background.

Looking at the lean principle value-focused planning \& development from (Khan et al., 2013), a misalignment or inefficacy seems to be happening among startups. Asking startups how actively they involve the customer during the PDP results in $65.4 \%$ stating that they actively involve the customer by filling in a $4 / 5$ or $5 / 5$. However, when looking at the methodology in which the $\mathrm{VoC}$ is translated to measurable product development specifications, $53.8 \%$ have no standardized approach and $26.9 \%$ defines it based on intuition. Improper translation of the $\mathrm{VoC}$ increases the causes of poor performance categorized under "defects" and other waste categories such as over processing and over production. This is in line with the results summarized in Table 5 which summarizes that the mentioned waste fields have a large impact on poor performance and delays during the PDP. 


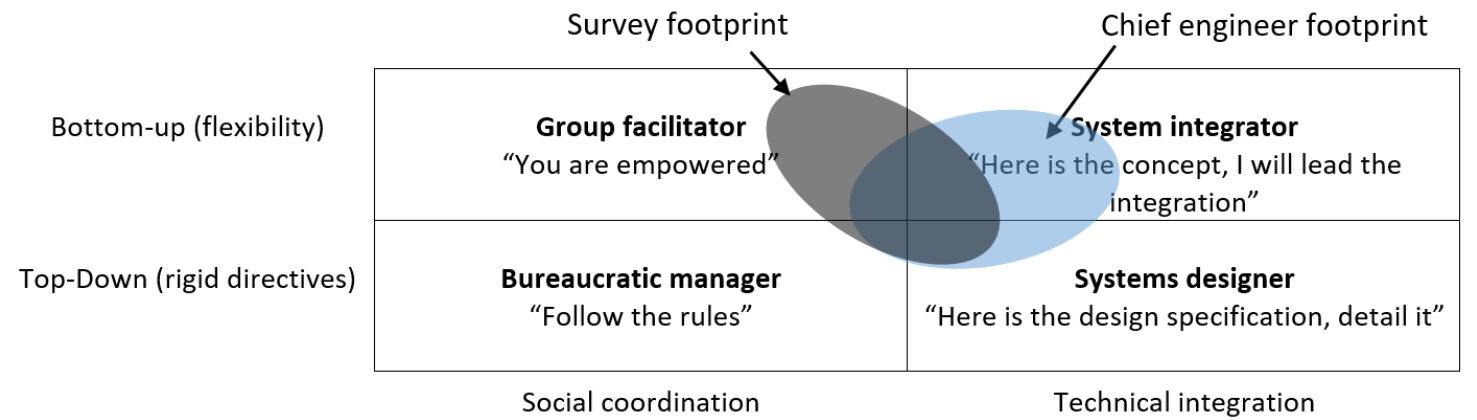

Figure 3. Chief engineer footprint compared to chief engineers present in the sample

\subsubsection{Opportunities and challenges of LPD implementation for startups}

Based on the results of the survey, the following challenges and opportunities are recognized which provide an overview of where LPD can potentially support tech startups with their PDP:

- Opportunity: documenting (tacit) knowledge after solving a design problem or when finishing an activity; $57.7 \%$ of the surveyed startups lack a good knowledge documentation. Creating more structure in knowledge documentation will likely decrease the problems related to the wastes over processing, over production, defects and movement which account for $84.3 \%$ of the causes of poor performance as shown in Table 5. Tools such as A3 single-sheet problem reports and building a knowledge based database creates structure making complex products easier to organize and tackle.

- Opportunity: translating VoC into measurable product development specifications; inefficacy in translating the VoC has a noticeable impact on the generated waste during the PDP. LPD has multiple tools and techniques such as VSM and QFD's to support the PDP to be more valuefocused. A strong focus on the customer needs/wants is one of the core principles of lean. This creates an opportunity for LPD to support startups. Standardizing the way in which the VoC is translated will likely decrease wastes related to defects, over processing, over production, movement and waiting.

- Opportunity: start with easy to implement tools and techniques; due to the limited resources of a startup, the focus of supporting the PDP should focus on the introduction of tools and techniques that are relatively easy and quick to implement. Tools such as QFD, kanban, checklists and experimenting with A3 single-sheet problems reports can be beneficial to introduce first. It is important to make clear that these tools and techniques however are not a solution and that a cultural change is needed to make it work (Morgan and Liker, 2006).

- Challenge: definition of a chief engineer; according to the results of this survey, the definition chief engineer differs from the originally defined version by Morgan and Liker. The challenge is to research how this difference affects the startups in the first stages of maturity and how this develops as it starts to grow. Research has to be done whether an adjustment of the original characteristics of a chief engineer is needed when applying it to startups or not.

- Challenge: limited resources; due to the lack of resources and budget, there is not enough time to experiment which method works best or to organize a pilot case within the company. The general LPD roadmap needs to be revised and adjusted where needed.

- Challenge: definition of LPD tools and techniques; it remains a challenge to prevent confusion and misalignment to what certain tools and techniques are as well as lean thinking itself. Increasing the knowledge on what lean and LPD are by means of additional courses in universities is recommended.

- Challenge: why is growth and introducing a product to market problematic?; according to the results of the survey and the ESM 2016 report growth and introduction to the market remain a challenge. More research is needed to better understand these challenges, to understand the root cause and how it can be supported by the use of lean tools and techniques. 


\section{Conclusion}

The paper presented empirically identified which challenges, that startups face, can be addressed by using LPD tools and techniques. A survey was developed to create a better understanding on how LPD could support startups with their PD. 104 Dutch tech startups received an invitation to fill in the survey from which 26 responded. Based on the results, characteristics of startups and their PDP are identified and connected to LPD which summarizes how this combination could support startups to survive in this dynamic world. With the identified opportunities and challenges that can be addressed with LPD, information is provided on which future research can be based on. The opportunities show that (tacit) knowledge management and translating the $\mathrm{VoC}$ into measurable product development specifications remains a difficult activity to manage and implement. Challenges when implementing LPD in startups is the current general definition of a chief engineer, the limited resources, and the definition of LPD tools and techniques. Results also indicated that startups in general have difficulties with growth and funding. It is important to find the root cause to why these problems occur and how it can be supported with the use of lean tools and techniques. The results of this study highlight the opportunities and challenges on how to reframe lean to startups specifically and inspires startups, SME's, and the academic world to look critically at LPD and PDP's.

With the opportunities and challenges defined, future research needs to be done to create a more indebt view of startups and their PDP. This research is currently ongoing, future steps will be to organize interviews to get a greater understanding of the mentioned challenges and opportunities and to develop a startup specific LPD implementation strategy which links LPD with startup maturity phases and the implementation threshold of tools. The following limitations of this research are present:

- The sample included Dutch tech startups only. To see whether geographical location has influence on the results, extending the research internationally creates a more holistic view.

- The opportunities and challenges defined in this research are hypotheses and need to be verified in further research to see what the impact will be and how it can be further optimized.

- There is, to our knowledge, not much research done on how LPD can support startups with their PD. More research is needed to create a better understanding of how their PD differs from large companies and what their limitations and advantages are when compared. This work serves as a basis on which further research can be built on.

\section{Acknowledgment}

The authors would like to thank the participating startups in this survey for sharing their knowledge and experiences and the startup hub Novel-T for spreading the survey in their newspaper.

\section{References}

Aikhuele, D.O. and Turan, F.M. (2016), "Proposal for a conceptual model for evaluating lean product development performance: A study of lpd enablers in manufacturing companies", IOP Conference Series: Materials Science and Engineering, Vol. 114 No. 1, pp. 012047. https://doi.org/10.1088/1757-899X/114/1/012047

Al-Ashaab, A., Golob, M., Urrutia, U.A., Gourdin, M., Petritsch, C. et al. (2015), "Development and application of lean product development performance measurement tool", International Journal of Computer Integrated Manufacturing, Vol. 29 No. 3, pp. 342-354. https://doi.org/10.1080/0951192X.2015.1066858

Dombrowski, U. and Zahn, T. (2011), "Design of a lean development framework", 2011 IEEE International Conference on Industrial Engineering and Engineering Management, Singapore, pp. 1917-1921. https://doi.org/10.1109/IEEM.2011.6118249

Eurostat (2017), European business economy - size class analysis. [online] Eurostat. Available at: http://ec.europa.eu/eurostat/statistics-explained/index.php/Archive:Business_economy_size_class_analysis\#Further_Eurostat_information (accessed: 30.08 .2017$)$.

Flores, M., Cabello, A., Torredemer, L., Agrawal, M., Keast, J. et al. (2011), "Do enterprises implement a process architecture towards lean in product development? A comparative study among large and small firms", 17th International Conference on Concurrent Enterprising, IEEE, Aachen, Germany, pp. 1-9.

Hoppmann, J., Rebentisch, E., Dombrowski, U., and Zahn, T. (2011), “A framework for organizing lean product development”, Engineering Management Journal, Vol. 23 No. 1, pp. 3-15. https://doi.org/10.1080/10429247.2011.11431883 
Khan, M., Al-Ashaab, A., Shehab, E., Haque, B., Ewers, P. et al. (2013), “Towards lean product and process development”, International Journal of Computer Integrated Manufacturing, Vol. 26 No. 12, pp. 1105-1116. https://doi.org/10.1080/0951192X.2011.608723

Kollmann, T., Stockmann, C., Hensellek, S. and Kensbock, J. (2016), European Startup Monitor, German Startup Association, Berlin.

Lewis, V.L. and Churchill, N.C. (1983), The five stages of small business growth. [online] Harvard Business Review. Available at: https://hbr.org/1983/05/the-five-stages-of-small-business-growth (accessed 14.09.2017).

Morgan, J. and Liker, J. (2006), The Toyota Product Development System: Integrating People, Process, and Technology, Productivity Press, New York.

Müller, R.M. and Thoring, K. (2012), "Design thinking vs. lean startup: A comparison of two user-driven innovation strategies", Leading Innovation through Design: Proceedings of the DMI 2012 International Research Conference, University of Virginia, pp. 181-192.

Nedre, N. (2018), How to choose between agile and lean, scrum and kanban; which methodology is the best? [online] RealtimeBoard Inc. Available at: https://realtimeboard.com/blog/choose-between-agile-lean-scrumkanban/\#.Wm73DTfkVaQ. (accessed: 04.01.2018).

Owens, J.D. (2007), "Why do some UK SMEs still find the implementation of a new product development process problematical?: An exploratory investigation", Management Decision, Vol. 45 No. 2, pp. 235-251. https://doi.org/10.1108/00251740710727269

Pullan, T.T., Bhasi, M. and Madhu, G. (2013), "Decision support tool for lean product and process development", Production Planning \& Control, Vol. 24 No. 6, pp. 449-464. https://doi.org/10.1080/09537287.2011.633374

Radeka, K. (2015), The Shortest Distance between You and Your New Product, Chesapeake Research Press, Washington.

Rauch, E., Dallasega, P. and Matt, D.T. (2017), "Critical factors for introducing lean product development to small and medium sized enterprises in Italy", Procedia CIRP, Vol. 60, pp. 362-367. https://doi.org/10.1016/j.procir.2017.01.031

Ries, E. (2011), The lean startup: how today's entrepreneurs use continuous innovation to create radically successful businesses, Crown Business, New York.

Schuh, G., Lenders, M., and Hieber, S. (2011), "Lean innovation: Introducing value systems to product development", International Journal of Innovation and Technology Management, Vol. 8, pp. 1129-1136. https://doi.org/10.1109/PICMET.2008.4599723

Scott, M. and Bruce, R. (1987), "Five stages of growth in small business", Long Range Planning, Vol. 20 No. 3 , pp. 45-52. https://doi.org/10.1016/0024-6301(87)90071-9

Stayton, J. and Mangematin, V. (2016), "Startup time, innovation and organizational emergence: A study of USAbased international technology ventures”, Journal of International Entrepreneurship, Vol. 14 No. 3, pp. 373409. https://doi.org/10.1007/s10843-016-0183-y

Tortorella, G.L., Marodin, G.A., Fettermann, D.d.C. and Fogliatto, F.S. (2016), "Relationships between lean product development enablers and problems", International Journal of Production Research, Vol. 54 No. 10, pp. 2837-2855. https://doi.org/10.1080/00207543.2015.1106020

Vohora, A., Wright, M. and Lockett, A. (2004), "Critical junctures in the development of university high-tech spinout companies”, Research Policy, Vol. 33 No. 1, pp. 147-175. https://doi.org/10.1016/S00487333(03)00107-0

Vossen, R.W. (1998), "Relative strengths and weaknesses of small firms in innovation", International Small Business Journal, Vol. 16 No. 3, pp. 88-94. https://doi.org/10.1177/0266242698163005

Ward, A.C. and Sobek II, D.K. (2014), Lean product and process development, Lean Enterprise Institute, Cambridge.

Womack, J. and Jones, D. (2003), Lean Thinking: Banish Waste and Create Wealth in Your Corporation, Free Press, New York.

Marlous Van Der Braak, MSc. student

University of Twente, Design, Production and Management

Kringsloot-west 20, 7722 WV Dalfsen, Netherlands

Email: marlousvanderbraak@gmail.com 